\title{
One-Year Outcome After Aneurysmal Subarachnoid Hemorrhage in Elderly Patients
}

Virta, Jyri J.

2020-11

Virta , J J , Satopää , J , Luostarinen , T \& Raj , R 2020 , ' One-Year Outcome After Aneurysmal Subarachnoid Hemorrhage in Elderly Patients ' , World Neurosurgery , vol. 143 , pp. E334-E343 . https://doi.org/10.1016/j.wneu.2020.07.127

http://hdl.handle.net/10138/335972

https://doi.org/10.1016/j.wneu.2020.07.127

cc_by_nc_nd

acceptedVersion

Downloaded from Helda, University of Helsinki institutional repository.

This is an electronic reprint of the original article.

This reprint may differ from the original in pagination and typographic detail.

Please cite the original version. 


\section{Journal Pre-proof}

One-year outcome after aneurysmal subarachnoid hemorrhage in elderly patients

Jyri J. Virta, MD PhD, Jarno Satopää, MD PhD, Teemu Luostarinen, MD PhD, Rahul Raj, MD PhD, Ass. Prof.

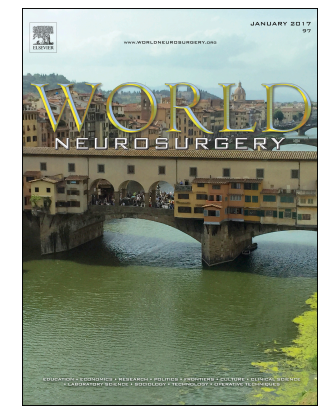

PII:

S1878-8750(20)31648-X

DOI:

https://doi.org/10.1016/j.wneu.2020.07.127

Reference: WNEU 15589

To appear in: World Neurosurgery

Received Date: 28 May 2020

Revised Date: 17 July 2020

Accepted Date: 18 July 2020

Please cite this article as: Virta JJ, Satopää J, Luostarinen T, Raj R, One-year outcome after aneurysmal subarachnoid hemorrhage in elderly patients, World Neurosurgery (2020), doi: https://doi.org/10.1016/ j.wneu.2020.07.127.

This is a PDF file of an article that has undergone enhancements after acceptance, such as the addition of a cover page and metadata, and formatting for readability, but it is not yet the definitive version of record. This version will undergo additional copyediting, typesetting and review before it is published in its final form, but we are providing this version to give early visibility of the article. Please note that, during the production process, errors may be discovered which could affect the content, and all legal disclaimers that apply to the journal pertain.

(c) 2020 Elsevier Inc. All rights reserved. 


\section{CRediT Author Statement}

Jyri J. Virta: Conceptualization, Formal analysis, Investigation, Writing - Original Draft Jarno Satopää: Conceptualization, Investigation, Writing - Review \& Editing Teemu Luostarinen: Conceptualization, Investigation, Writing - Review \& Editing Rahul Raj: Conceptualization, Investigation, Writing - Review \& Editing 
Title: One-year outcome after aneurysmal subarachnoid hemorrhage in elderly patients

Authors: MD PhD. Jyri J. Virta ${ }^{1,2}$, MD PhD. Jarno Satopää ${ }^{1}$, MD PhD. Teemu Luostarinen $^{3}$, Ass. Prof. MD PhD. Rahul Raj ${ }^{1}$

Affiliations: 1 Department of Neurosurgery, Neurocenter, Helsinki University Hospital and University of Helsinki, Finland; 2 Department of Neurology, Neurocenter, Helsinki University Hospital and University of Helsinki, Finland; 3 Division of Anesthesiology, Department of Anesthesiology, Intensive Care and Pain Medicine, University of Helsinki and Helsinki University Hospital

Corresponding author: Jyri J. Virta, MD, PhD, e-mail: jyri.virta@hus.fi, phone: +358406309958, fax: +358947187560, ORCID: 0000-0002-5150-938X

Key words: subarachnoid hemorrhage, aged, prognosis

Short title: Outcome after aneurysmal SAH in the elderly 


\section{Abstract}

Background: The number of elderly aneurysmal subarachnoid hemorrhage (aSAH) patients admitted to intensive care units (ICU) has increased. We aimed to analyze the characteristics and outcomes of such patients in a tertiary university hospital during a fiveyear period.

Methods: A retrospective, single-center analysis of aSAH patients $\geq 70 \mathrm{y}$ old admitted to a tertiary neuro-ICU during January 2014-May 2019 based on medical records and computed tomography scans. The primary outcome was functional outcome at 12 months. We used multivariable logistic regression to assess factors associated with unfavorable outcome (Glasgow Outcome Scale 1-3 and institutionalized).

Results: Of 117 included patients, $49 \%$ had a favorable outcome at 12 months, while mortality was $41 \%$. In multivariable analysis, poor grade aSAH and intraventricular hemorrhage were predictors of poor outcome (odds ratio 4.7, $95 \% \mathrm{Cl}$ 1.7-12.5 and 2.8, $95 \%$ Cl 1.1-7.2, respectively). None of the patients with a Glasgow Coma Scale (GCS) motor score 1-3 three days after admission were alive at 12 months. In contrast, $65 \%$ of those with a GCS motor score 6 had favorable outcome.

Conclusions: Half of elderly aSAH patients admitted to a neuro-ICU were able to live at home after 12 months. Mortality was significant, but the number of severely disabled patients was low. Clinical status at admission was the strongest predictor of outcome, while intraventricular hemorrhage increased the risk of poor outcome as well. GCS motor score three days after admission seemed to predict mortality and outcome. 


\section{Introduction}

As the expected lifespan has increased during the last decades, the number of active and functional elderly people has increased. This, together with the appreciation of aneurysmal subarachnoid hemorrhage (aSAH) as a vascular disease with lifelong modifiable risk factors, ${ }^{1}$ has led to an increased number of elderly patients treated at intensive care units (ICU) with improved outcomes. ${ }^{2}$ Still, with limited resources, it is imperative to know the expected outcomes and indicators of unfavorable outcome in these patients.

Previous studies on elderly aSAH patients have reported favorable outcomes in $18-46 \%$ of patients, ${ }^{3-8}$ but have e.g. included only few poor-grade patients ${ }^{6}$ or a large proportion of patients who did not receive active aneurysm treatment. ${ }^{5}$ To add to this knowledge, we evaluated all $\geq 70$ years old aSAH patients treated at the neuro-ICU of a tertiary university hospital during the last 5 years. We assessed the current clinical characteristics, outcomes and risk factors for unfavorable functional outcome in this age group of aSAH patients, and hypothesized that outcomes in elderly aSAH patients have improved in the last years, especially for good grade aSAH patients. 


\section{Material and methods}

\section{Study setting and population}

We conducted a single-center retrospective study including elderly patients ( $\geq 70$ years) admitted to the neuro-ICU of Helsinki University Hospital between January 2014 and May 2019. The local institutional research committee approved the study and waived the need for patient consent (HUS/466/2019 §106). The study was conducted according to the Strengthening the Reporting of Observational studies in Epidemiology (STROBE) Statement.

We screened all $\geq 70$ years old patients admitted to the neuro-ICU and identified those with an International Statistical Classification of Diseases and Related Health Problems (ICD) 10 code of I60.0-9 (including non-traumatic SAH from specific arteries and unspecified nontraumatic SAH) between January 2014 and May 2019. We then evaluated all patients and included only those with a verified aSAH and excluded those with other etiologies.

\section{Data collection}

After selecting patients eligible for the analyses, we scrutinized electronic health records and imaging data. We extracted the following variables: age at admission, sex, Charlson Comorbidity Index $(\mathrm{CCl}),{ }^{9}$ use of antithrombotic medication (antiplatelets or anticoagulants), time from ictus to admission ( $<12$ hours, $12-24$ hours, $>24$ hours), the World Federation of Neurological Surgeons (WFNS) grading scale, ${ }^{10}$ Glasgow Coma Scale motor score ${ }^{11}$ (GCS-m) 3 days (60-84 hours) after admission, location and size of the ruptured aneurysm, treatment modality (surgical or endovascular), and presence of acute hydrocephalus requiring treatment on admission or later at the neuro-ICU (i.e. an external ventricular drain [EVD]). If a patient was intubated before admission at our hospital, we used the last recorded GCS score before intubation to estimate the patient's WFNS score. Regarding the GCS-m at 3 days, skilled 
neurointensive nurses tests routinely the GCS components following the wake-up test, in which sedation is transiently ceased. ${ }^{12}$ Only GCS-m instead of overall GCS was recorded as a large proportion of patients were intubated 3 days after admission, making overall GCS assessment unreliable.

We evaluated the characteristics of the aSAH including a thick and diffuse bleeding pattern (clot thickness $\geq 4 \mathrm{~mm}$ in $\geq 3$ cisterns), any intraventricular hemorrhage (IVH) regardless of volume or number of ventricles affected and intracerebral hemorrhage (ICH) from computed tomography (CT) scans on admission. In addition, we recorded data regarding chronic post-SAH hydrocephalus requiring a shunt, and vasospasm. We diagnosed vasospasm based upon clinical symptoms and/or radiological findings. If a patient developed new neurological deficits not attributable to a previous focal lesion with radiological vasospasm on CT angiography (CTA), we initiated vasospasm treatment (intravenous nimodipine infusion and augmented hypertension) if feasible. If reliable neurological assessment was not possible due to intubation and severe radiological vasospasm was observed, we initiated treatment. If reliable neurological assessment was possible, the presence of radiological vasospasm without clinical findings did not justify treatment. If a patient developed new CT hypodensities outside the direct vicinity of a previous focal lesion, we considered it a sign of delayed cerebral ischemia and initiated treatment. We did not use perfusion-CT in vasospasm diagnosis, as we were unable to perform the perfusion maps most sensitive for vasospasm (e.g. time to drain). ${ }^{13}$

We classified possible limitations of care during the stay in the neuro-ICU into three groups: donot-resuscitate (DNR), weaning of life-supportive care, and treatment as a possible organ donor. Only the gravest limitation was recorded.

A flow-chart of our data collection is shown in Supplemental Figure 1. 


\section{Outcomes}

Our primary outcome of interest was functional outcome at 12 months after aSAH. We defined favorable outcome as Glasgow Outcome Scale (GOS) ${ }^{11} 3-5$ with the patient living at home, and unfavorable outcome as GOS 1-3 with the patient institutionalized. Thus, a patient with a GOS of 3 living at home with or without home care service was classified as having a favorable outcome and a patient with a GOS of 3 being institutionalized (i.e. staying in a nursing home or hospital) as having an unfavorable outcome. We also looked at the same outcome measures at 3 months and all-cause mortality as of November $11^{\text {th }}, 2019$. The authors assessed the outcomes retrospectively from medical records.

\section{Statistical analyses}

As none of the continuous variables were normally distributed (according to the ShapiroWilk test and visual inspection of histograms), we report median and interquartile range (IQR) values. We report frequencies for categorical variables. For the primary outcome, we performed univariate and multivariable logistic regression analysis to estimate odds ratios (OR) with 95\% confidence intervals (Cl) for unfavorable outcome. Reference group for each factor is described in the results. The multivariable model included age as a continuous variable, aSAH grade, presence acute hydrocephalus treated with an EVD, presence of IVH, and presence of $\mathrm{ICH}$. Additionally, we performed a sensitivity analysis including only patients with a treated aneurysm.

For all-cause mortality, we performed Kaplan-Meier analysis using the log rank test to test for differences between groups. We report estimated mean survival times with $95 \% \mathrm{Cls}$.

We analyzed age both as a continuous and categorical ( $70-74$ years, $75-79$ years, $\geq 80$ years) variable, and dichotomized aSAH severity into good and poor grades (WFNS I-III and WFNS 
IV-V, respectively). We divided $\mathrm{CCI}$ into three groups: 3,4 and $\geq 5$ points (none of the patients had a CCl score of $<3$ ).

As we expected there to be few missing values, we excluded those with missing values from the comparison analyses. We considered $p$-values $<0.05$ as statistically significant in all analyses. We used SPSS Statistics version 25.0 for Mac (IBM Corp, Armonk, NY, USA) for all analyses.

\section{Ethics approval}

The local institutional research committee approved the study and waived the need for patient consent (HUS/466/2019 §106). The study was conducted according to the Strengthening the Reporting of Observational studies in Epidemiology (STROBE) Statement. 


\section{Results}

\section{Baseline and clinical characteristics}

We included a total of 117 patients. Patient baseline characteristics are shown in Table 1. Briefly, median age was 76 years (IQR $73-80$ ), $80 \%$ were female and $41 \%$ had a poor grade aSAH, 32\% were on some form of antithrombotic medication prior to admission and $47 \%$ had a $\mathrm{CCl}$ of 3 . Of all patients, four (3\%) were initially treated as potential organ donors (i.e. received no active treatment).

Eighty percent of ruptured aneurysms were located in the anterior circulation. The most frequent aneurysm location was anterior communicating artery ( $n=34,29 \%)$. Median aneurysm size was $7.0 \mathrm{~mm}$ (IQR 4.7-10.0). The aneurysm location for three patients was not available (no or only poor-quality angiographic studies or cessation of intracranial circulation prior to angiography).

Of the 117 patients, 96 patients ( $82 \%$ of all) underwent either microsurgical ( $n=36,38 \%$ of treated) or endovascular ( $n=60,62 \%$ of treated) treatment for the ruptured aneurysm, while 21 patients ( $18 \%$ of all) received only medical treatment (poor prognosis [ $n=19]$, other reasons [n=2]). Median length of stay in the ICU was 6 days (IQR 3-14) and 10 patients required ICU readmission.

Of all 117 patients, 20 (17\%) died during the first week and 10 (9\%) died in the ICU. Of the 97 patients alive seven days after admission, 24 patients (25\%) developed vasospasm. Of the 89 patients alive 14 days after admission, 31 patients (35\%) required a shunt for postSAH hydrocephalus. Of the 107 ICU survivors, six patients (6\%) were discharged home, 87 
patients (81\%) were discharged to a lower level of care treatment unit/rehabilitation, and 14 patients (13\%) had a fatal outcome at our hospital.

\section{Outcome at 3 and 12 months}

Data on 3-month and 12-month functional outcome was available for 114 (97\%) and 115 patients (98\%), respectively. For those alive at 3 and 12 months, the median follow-up times from admission were 102 days (IQR 86-121) and 360 days (IQR 298-473), respectively.

At 3 months, 48 patients (42\%) had a favorable outcome. Likewise, at 12 months, 56 patients (49\%) had favorable outcome. In regard to mortality, 38 (33\%) and 47 (41\%) patients had died before the 3 and 12-month follow-up, respectively. Detailed information about the functional outcomes at 3 and 12 months is shown in Figure 1.

When including only patients with a treated aneurysm, 47 of 93 patients (51\%) had favorable outcome at 3 months and 56 of 94 patients (60\%) at 12 months. Detailed outcomes of these patients are shown in Supplemental Figure 2.

\section{Risk factors for unfavorable outcome at 12 months}

Including all 115 patients, poor-grade aSAH (OR 5.8, 95\% Cl 2.5-13.5, $\mathrm{p}<0.01$, compared to good-grade aSAH), thick and diffuse bleeding pattern (OR 3.2, 95\% $\mathrm{Cl} 1.3-8.1, p=0.01$ ) and presence of IVH (OR 4.0, 95\% Cl 1.7-9.2, p<0.01) were significantly associated with unfavorable outcome in univariate analysis (Table 2 ). In contrast, age, $\mathrm{CCl}$, sex, antithrombotic medication, presence of $\mathrm{ICH}$, or acute hydrocephalus treated with an EVD were not significantly associated with our primary outcome.

In those patients who had their IA treated $(n=94)$, there was no difference in outcome between surgical and endovascular treatment of the aneurysm (OR 1.9, 95\% Cl 0.8-4.4, 
$p=0.16, n=94)$. In patients alive at seven days after admission ( $n=95)$, vasospasm was not associated with unfavorable outcome (OR $0.6,95 \% \mathrm{Cl} 0.2-1.7, \mathrm{p}=0.38)$. Likewise, when considering only patients alive at 14 days $(n=87)$, chronic post-SAH hydrocephalus was not associated with unfavorable outcome (OR 1.3, $95 \% \mathrm{Cl} 0.5-3.3, p=0.54, n=87)$.

In the multivariable logistic regression model, including age as a continuous variable, aSAH grade, presence of acute hydrocephalus treated with an EVD, presence of IVH, and presence of ICH, only poor-grade aSAH and IVH increased the risk of unfavorable outcome at 12 months (OR 4.7, $95 \% \mathrm{Cl}$ 1.7-12.5, $\mathrm{p}<0.01$, and $\mathrm{OR} 2.8,95 \% \mathrm{Cl} 1.1-7.2, \mathrm{p}=0.03$, respectively, Table 3).

In the sensitivity analysis including only patients with a treated aneurysm, aSAH grade and presence of IVH remained significant risk factors for unfavorable outcome at 12 months in univariate analyses. In multivariate analysis, none of the variables significantly affected outcome (Supplemental Table).

\section{Risk factors for unfavorable outcome at 3 months}

In univariate analysis including all 114 patients, poor-grade aSAH, thick and diffuse bleeding pattern, presence of IVH and presence of ICH were significantly associated with unfavorable outcome (Table 2). When considering only patients alive at seven days after admission $(n=95)$, vasospasm was not associated with unfavorable outcome (OR 1.3, 95\% $\mathrm{Cl} 0.5-3.4$, $p=0.55)$. Among the patients alive 14 days after admission $(n=86)$, requirement of a shunt for post-SAH hydrocephalus was associated with an increased risk of unfavorable outcome at 3 months (OR $3.4,95 \% \mathrm{Cl} 1.3-8.5, \mathrm{p}=0.01)$. 
In the multivariable logistic regression model, only poor-grade SAH increased the risk of poor outcome (OR 5.8, $95 \% \mathrm{Cl} 2.0-16.4, \mathrm{p}<0.01$, Table 3).

\section{GCS motor score at 3 days and 12-month outcome}

Both GCS-m 3 days after admission and 12-month outcome information were available for 112 patients. Of these, 101 (90\%) were alive 3 days after admission. Of those alive at 3 days, $11(11 \%)$ had a GCS-m of $1-3$, none of whom were alive at 12 months; 14 patients (14\%) had a GCS-m of 4-5 and five of them (36\%) had a favorable outcome at 12 months; whereas 76 patients (75\%) had a GCS-m 6, of whom 49 (65\%) had a favorable outcome at 12 months. The outcome differences between these GCS-m groups were highly significant (Chi-Square $18.1, p<0.01)$

Life-supporting care was actively withdrawn during the first three days after admission in $36 \%$ of the patients with GCS-m $1-3$, in $7 \%$ of those with a GCS-m of $4-5$, and in $4 \%$ of those with GCS-m of 6.

\section{Mortality analysis}

Mortality data as of November $11^{\text {th }}, 2019$ and eventual time of death were available for all included patients except for one patient living abroad. For those who died during follow-up, the mean time from admission to death was 5.1 months (standard deviation [SD] 156.0]. For survivors, the mean follow-up time from admission to data collection was 29.9 months (SD 19.1). The estimated mean survival time for all patients was 36.6 months ( $95 \% \mathrm{Cl} 30.8$ 42.4), and differed significantly between good and poor grade aSAH $(49.3$ months, $95 \% \mathrm{Cl}$ 43.0-55.7 vs. 17.7 months, $95 \%$ Cl 9.6-25.8, respectively). Kaplan-Meir graphs for both groups are shown in Figure 2. Patients with a poor grade SAH had significantly shorter lifeexpectancies (Log Rank $\mathrm{p}<0.01$ ). 


\section{Discussion}

\section{Key findings}

In this consecutive, retrospective single-center study of elderly ( $\geq 70$ years) aSAH patients we found that $42 \%$ of patients had a favorable outcome three months after aSAH and $49 \%$ had a favorable outcome after 12 months (i.e. were able to live at home). In parallel to this, mortality increased from $33 \%$ to $41 \%$ between three and 12 months, and the proportion of patients living in an institution decreased from $25 \%$ to $10 \%$. Overall, this indicates that while a significant portion of patients die during the first year, the majority of survivors are able to continue living at home, and that there is potential for functional recovery between 3 and 12 months after aSAH also in elderly patients. Also, an important consideration when treating critically ill elderly patients is the possibility of increasing the number of severely disabled patients, but in our study the proportion of such patients at was low. Our results are based on a selected, previously rather healthy elderly population admitted to a university hospital neuro-ICU and, therefore, cannot be generalized to all elderly aSAH patients.

Further, we found that none of the patients with a GCS-m 1-3 three days after admission survived. To our knowledge, this is the first study to report an association between the patients' motor score three days after admission and prognosis at 12 months. We chose this time point because the detrimental effect of acute hydrocephalus had most likely eased before this due to insertion of an EVD. Consequently, we found that none of those with GCS-m 1-3 three days after admission were alive at 12 months. In contrast, $65 \%$ of patients with GCS-m 6 at three days had a favorable outcome. The number of patients in each group was quite low, and due to limitations of care during the first 3 days, we cannot rule out the 
effect of a self-fulfilling prophecy. However, the signal is quite strong, and the finding warrants further validation as it could help in clinical decision-making.

The strongest prognostic factor for poor outcome was clinical aSAH grade at admission, as two thirds of patients with WFNS I-III aSAH had favorable outcome at 12 months. In contrast, only a quarter of patients with WFNS IV-V aSAH had favorable outcome, which is still a significant proportion of patients. Additionally, presence of IVH increased the odds of poor outcome at 12 months. In contrast, age, $\mathrm{CCl}$, sex, antithrombotic medication or presence of ICH were not associated with outcome. There were no differences in the outcomes between surgical and endovascular treatments. The risk factors for poor outcome in the elderly seem to be similar to those of all SAH patients ${ }^{14}$, but due to the study design we cannot compare the odds of poor outcome with younger patients.

Acute hydrocephalus at admission or during hospitalization treated with an EVD was not associated with outcome at 3 or 12 months. In contrast, chronic post-SAH hydrocephalus decreased the odds of favorable outcome at 3 months, but not at 12 months. In total, $60 \%$ of patients requiring a shunt were able to live at home 12 months after aSAH. This indicates that chronic post-SAH hydrocephalus does not permanently hinder good recovery but makes the recovery process slower, as patients' recovery is temporarily halted before the shunt operation. Elderly patients can already have borderline issues with CSF absorption as well as decreased brain compliance. Therefore, a more proactive stance in considering shunting at an earlier stage may be indicated in the elderly aSAH patients to hasten their recovery. 


\section{Comparison with previous studies}

Our results are mainly in line with previous studies reporting favorable outcome in $40 \%$ of all elderly aSAH patients at one year, ${ }^{3}$ and good-to-moderate recovery at 6 months in $24 \%$ of elderly patients with poor-grade aSAH. ${ }^{4}$ Goldberg et al. ${ }^{5}$ reported favorable outcomes only in only $18 \%$ of poor grade aSAH patients aged $70-79$ years, but the ruptured aneurysm was treated only in half of these patients. Ryttlefors et al. ${ }^{6}$ reported good outcome at 1 year in $58 \%$ of $\geq 65$ years old aSAH patients in a prospective study, but only $7 \%$ of patients had a poor-grade aSAH. Tacconi et al. found that $46 \%$ of patients $\geq 80$ years had a favorable outcome at a median follow-up time of 12 months. ${ }^{7}$ In a prospective study from France, Proust et al. found that $57 \%$ of elderly patients (>70 years) with a good grade SAH (WFNS IIII) had a favorable functional outcome at one-year after SAH. ${ }^{8}$ Acute hydrocephalus has been reported to worsen outcome, ${ }^{2,15}$ but this was not seen in our analyses.

Increasing age did not affect outcome in our analyses. This possibly reflects the fact that only previously rather healthy elderly patients were admitted to the neuro-ICU. The CCI distribution further emphasizes this, as $78 \%$ of patients had a $\mathrm{CCl}$ of 3-4 even though all our patients got a score of at least 3 based on age alone ${ }^{9}$. Based on mortality data from Statistics Finland, we estimate that approximately $50 \%$ of all over 70 -year-old SAH patients from the catchment area of our university hospital were treated at our neuro-ICU (data available upon request from Statistics Finland, https://www.tilastokeskus.fi/til/ksyyt/index_en.html"). This implies that a significant proportion of elderly aSAH patients either died before hospital admission or were not admitted to our ICU, most likely due to assumed poor prognosis and, hence, did not receive treatment of the aneurysm nor neurointensive care. 
In contrast to our results, Goldberg et al. found that increasing age worsened outcome when including patients $\geq 60$ years old treated in a tertiary care center. However, as stated above, only half of those $\geq 70$ years old received treatment of the ruptured aneurysm, which distorts the outcomes towards the worse, as up to $89 \%$ of patients with a ruptured but untreated aneurysm die within one year of rupture. ${ }^{5,16}$ Park et al. found that increasing age worsened outcome in 70-90 years old patients, but they in contrast included only patients with a treated aneurysm. ${ }^{3}$ Therefore, none of the previous studies is representative of the entire elderly population.

\section{Strengths and limitations}

There are some strengths of this study that should be highlighted. We were able to analyze a consecutive series of patients with broad inclusion criteria and, hence, our results are likely to reliably describe outcomes in patients treated at a university hospital. Our tertiary hospital is the only institute providing neurointensive care in our province of 2 million people, and therefore, all the patients that received active treatment are included in the series. We had extensive data regarding the patients' clinical status at admission and also during their stay at the neuro-ICU, development of acute hydrocephalus, and radiological features of the aSAH. We were also able to follow our patients for 12 months with only two subjects lost to follow-up. It is generally appreciated that recovery from a serious central nervous disorder can take up to a year. Our dichotomization of functional outcome into favorable and unfavorable was significant both on a personal and societal level, as it differentiated elderly patients who were able to return home after a serious cerebral insult from those who had to be institutionalized. When considering younger aSAH patients, it may not be appropriate to consider a GOS of three as favorable outcome, as these patients 
still have severe disability requiring daily help, but we found our dichotomization adequate for older patients. However, this did increase the proportion of patients with favorable outcome. Even though outcome was assessed retrospectively, we think the GOS classification could be done reliably as we had access to extensive communal medical records.

When considering younger aSAH patients, it may not be appropriate to consider a GOS of three as favorable outcome, as these patients still have severe disability requiring daily help, but we found our dichotomization adequate for older patients. However, our dichotomization did increase the proportion of patients with favorable outcome.

There are some study limitations that should be mentioned. Due to the retrospective design of our study, we cannot rule out that the treating clinicians' position on an individual patient's prognosis has impacted treatment decisions and, hence, our results. This e.g. likely explains why vasospasm was not associated with poor outcome, as patients whose prognosis was already deemed poor possibly did not receive treatment for their potential vasospasm, or patients already in poor condition did not tolerate treatment with augmented hypertension. However, there is some evidence that vasospasm occurs less often in the elderly, and the incidence of vasospasm in our study is line with previous literature. ${ }^{17}$ Regarding risk factor assessment for outcome after aSAH it is important to notice that this is a hospitalized cohort and thus, there is a risk of survival bias affecting the association between risk factors and outcome. ${ }^{18}$ 


\section{Conclusions}

According to our findings, active treatment of aSAH among elderly people is worthwhile, especially in those with good clinical status at admission. Level of consciousness indicated by GCS-m at three days after admission seems to be a strong indicator of patient outcome, but this finding needs further validation.

\section{Funding}

Independent funding support has been received from Helsinki University Hospital (State funding, Finland). Dr. Virta has received an independent research grand from from Maire Taponen's Foundation. Dr. Raj has received independent research grants from Medicinska Understödsföreningen Liv \& Hälsa and Finska Läkaresällskapet.

\section{Declarations of Interest}

None. 


\section{References}

1. Korja M, Silventoinen K, Laatikainen T, et al. Risk Factors and Their Combined Effects on the Incidence Rate of Subarachnoid Hemorrhage - A Population-Based Cohort Study. Berthold HK, ed. PLoS One. 2013;8(9):e73760. https://doi:10.1371/journal.pone.0073760

2. Johansson M, Cesarini KG, Contant CF, Persson L, Enblad P. Changes in Intervention and Outcome in Elderly Patients With Subarachnoid Hemorrhage. Stroke. 2001;32(12):2845-2949. https://doi:10.1161/hs1201.099416

3. Park J, Woo H, Kang D-H, Kim Y. Critical age affecting 1-year functional outcome in elderly patients aged $\geq 70$ years with aneurysmal subarachnoid hemorrhage. Acta Neurochir (Wien). 2014;156(9):1655-1661. https://doi:10.1007/s00701-014-2133-6

4. Ryttlefors M, Howells T, Ronne-Engström E, Nilsson P, Enblad P. Neurointensive care is justified in elderly patients with severe subarachnoid hemorrhage-an outcome and secondary insults study. Acta Neurochir (Wien). 2010;152(2):241-249. https://doi:10.1007/s00701-009-0496-x

5. Goldberg J, Schoeni D, Mordasini P, et al. Survival and Outcome After Poor-Grade Aneurysmal Subarachnoid Hemorrhage in Elderly Patients. Stroke. 2018;49(12):28832889. https://doi:10.1161/STROKEAHA.118.022869

6. Ryttlefors M, Enblad P, Kerr RSC, Molyneux AJ. International subarachnoid aneurysm trial of neurosurgical clipping versus endovascular coiling: subgroup analysis of 278 elderly patients. Stroke. 2008;39(10):2720-2726.

https://doi:10.1161/STROKEAHA.107.506030

7. Tacconi L, Spinelli R, Signorelli F. Subarachnoid hemorrhage in the eighties: to treat or not to treat. J Neurosurg Sci. Published online October 28, 2019.

https://doi:10.23736/S0390-5616.19.04743-X

8. Proust $F$, Bracard S, Thines $L$, et al. Functional outcome 1 year after aneurysmal subarachnoid hemorrhage due to ruptured intracranial aneurysm in elderly patients. Neurochirurgie. Published online December 18, 2019. https://doi:10.1016/j.neuchi.2019.11.002

9. Charlson ME, Pompei P, Ales KL, MacKenzie CR. A new method of classifying prognostic comorbidity in longitudinal studies: Development and validation. $J$ Chronic Dis. 1987;40(5):373-383. https://doi:10.1016/0021-9681(87)90171-8

10. Drake C, Hunt W, Sano K, Kassell N, Teasdale G, Pertuiset B. Report of World Federation of Neurological Surgeons Committee on a Universal Subarachnoid Hemorrhage Grading Scale. J Neurosurg. 1988;68(6):985-986.

https://doi:10.3171/jns.1988.68.6.0985

11. Teasdale G, Jennett B. Assessment of coma and impaired consciousness. A practical scale. Lancet. 1974;304(7872):81-84. https://doi:10.1016/S0140-6736(74)91639-0 
12. Marklund N. The Neurological Wake-up Test-A Role in Neurocritical Care Monitoring of Traumatic Brain Injury Patients? Front Neurol. 2017;8:540.

https://doi:10.3389/fneur.2017.00540

13. Othman AE, Afat $\mathrm{S}$, Nikoubashman $\mathrm{O}$, et al. Volume perfusion $\mathrm{CT}$ imaging of cerebral vasospasm: diagnostic performance of different perfusion maps. Neuroradiology. 2016;58(8):787-792. https://doi:10.1007/s00234-016-1695-9

14. Zheng $\mathrm{K}$, Zhong $\mathrm{M}$, Zhao $\mathrm{B}$, et al. Poor-grade aneurysmal subarachnoid hemorrhage: Risk factors affecting clinical outcomes in intracranial aneurysm patients in a multicenter study. Front Neurol. 2019;10(FEB). https://doi:10.3389/fneur.2019.00123

15. Brawanski N, Kunze F, Bruder M, et al. Subarachnoid Hemorrhage in Advanced Age: Comparison of Patients Aged 70-79 Years and 80 Years and Older. World Neurosurg. 2017;106:139-144. https://doi:10.1016/j.wneu.2017.06.056

16. Korja M, Kivisaari R, Rezai Jahromi B, Lehto H. Natural History of Ruptured but Untreated Intracranial Aneurysms. Stroke. 2017;48(4):1081-1084.

https://doi:10.1161/STROKEAHA.116.015933

17. Wachter D, Hans F, Kreitschmann-Andermahr I, Rohde V. Lower incidence of transcranial Doppler and symptomatic vasospasm after aneurysmal subarachnoid hemorrhage and aneurysm clipping in the elderly patient? Neurosurgery. 2011;69(2):261-266; discussion 266-7. https://doi:10.1227/NEU.0b013e31821d2b49

18. Lindbohm J V., Kaprio J, Korja M. Survival bias explains improved survival in smokers and hypertensive individuals after aSAH. Neurology. 2019;93(23):e2105-e2109. https://doi:10.1212/WNL.0000000000008537 


\section{Figure Captions}

Figure 1. The distribution of functional outcomes at 3 and 12 months after aneurysmal subarachnoid hemorrhage according to Glasgow Outcome Scale. The numbers in the bars indicate the number of patients in each group. Favorable outcome has a green background and unfavorable a red background

Figure 2. Kaplan-Meier survival graphs for World Federation of Neurosurgical Societies grading scale (WFNS) I-III ( $n=68$, solid line) and WFNS IV-V ( $n=47$, dotted line) patients 
Table 1

Demographic, clinical and radiologic characteristics of the 117 patients included in the study. Number and proportion of patients in each group is shown.

\begin{tabular}{|c|c|c|c|}
\hline \multirow{4}{*}{ Age at admission (years) } & & $\mathbf{n}$ & $\%$ \\
\hline & $70-74$ years & 53 & $(45,3 \%)$ \\
\hline & $75-79$ years & 37 & $(31,6 \%)$ \\
\hline & $>=80$ years & 27 & $(23,1 \%)$ \\
\hline \multirow[t]{2}{*}{ Sex } & Female & 94 & $(80,3 \%)$ \\
\hline & Male & 23 & $(19,7 \%)$ \\
\hline \multirow[t]{3}{*}{$\mathrm{CCl}^{\mathrm{a}}$} & 3 & 55 & $(47,4 \%)$ \\
\hline & 4 & 36 & $(31,0 \%)$ \\
\hline & $>=5$ & 25 & $(21,6 \%)$ \\
\hline \multirow{3}{*}{ Antithrombotic medication } & None & 80 & $(68,4 \%)$ \\
\hline & Antiplatelet & 22 & $(18,8 \%)$ \\
\hline & Anticoagulant & 15 & $(12,8 \%)$ \\
\hline \multirow[t]{3}{*}{ Delay from ictus to admission } & $<12 \mathrm{~h}$ & 79 & $(67,5 \%)$ \\
\hline & $12-24 \mathrm{~h}$ & 12 & $(10,3 \%)$ \\
\hline & $>24 \mathrm{~h}$ & 26 & $(22,2 \%)$ \\
\hline \multirow[t]{5}{*}{ WFNS at admission* } & 1 & 40 & $(34,5 \%)$ \\
\hline & II & 19 & $(16,4 \%)$ \\
\hline & III & 10 & $(8,6 \%)$ \\
\hline & IV & 16 & $(13,8 \%)$ \\
\hline & $\mathrm{V}$ & 31 & $(26,7 \%)$ \\
\hline \multirow[t]{3}{*}{ Bleeding characteristics* } & Thick and diffuse clot & 89 & $(76,7 \%)$ \\
\hline & Presence of IVH & 77 & $(66,4 \%)$ \\
\hline & Presence of $\mathrm{ICH}$ & 44 & $(37,9 \%)$ \\
\hline \multirow{3}{*}{ Aneurysm location } & Anterior circulation & 93 & $(79,5 \%)$ \\
\hline & Posterior circulation & 21 & $(17,9 \%)$ \\
\hline & Unknown & 3 & $(2,6 \%)$ \\
\hline \multirow[t]{3}{*}{ Treatment modality } & None & 21 & $(17,9 \%)$ \\
\hline & Endovascular & 60 & $(51,3 \%)$ \\
\hline & Surgical & 36 & $(30,8 \%)$ \\
\hline \multirow[t]{4}{*}{ Limitation of care } & None & 76 & $(65,0 \%)$ \\
\hline & DNR & 18 & $(15,4 \%)$ \\
\hline & Weaning of life-supportive care & 19 & $(16,2 \%)$ \\
\hline & Treated as a potential organ donor & 4 & $(3,4 \%)$ \\
\hline \multirow[t]{3}{*}{ SAH complications } & Vasospasm & 24 & $(20,5 \%)$ \\
\hline & Acute hydrocephalus & 61 & $(52,1 \%)$ \\
\hline & Chronic hydrocephalus & 31 & $(26,5 \%)$ \\
\hline \multirow[t]{3}{*}{ Discharge from ICU } & Step-down unit & 57 & $(48,7 \%)$ \\
\hline & Ward & 50 & $(42,7 \%)$ \\
\hline & Died in the ICU & 10 & $(8,5 \%)$ \\
\hline \multirow[t]{4}{*}{ Discharge from university hospital } & Step-down unit & 4 & $(3,4 \%)$ \\
\hline & Hospital or primary care ward & 83 & $(70,9 \%)$ \\
\hline & Home & 6 & $(5,1 \%)$ \\
\hline & $\begin{array}{l}\text { Discharged from the ICU but died before } \\
\text { discharge }\end{array}$ & 14 & $(12,0 \%)$ \\
\hline \multirow{2}{*}{ Mortality } & Within 7 days & 20 & $(17,1 \%)$ \\
\hline & Within 14 days & 28 & $(23,9 \%)$ \\
\hline
\end{tabular}

* one missing value

$\mathrm{CCl}$ : Charlson Comorbidity Index, ICH: intracerebral hemorrhage, IVH: intraventricular hemorrhage, WFNS: World Federation of Neurosurgical Societies grading scale 


\section{Table 2}

Results of the univariate logistic regression analyses for outcomes at 3 and 12 months after aneurysmal subarachnoid hemorrhage. Proportion of patients with favorable and unfavorable as well as odds ratios with $95 \%$ confidence intervals for unfavorable outcome are shown.

\begin{tabular}{|c|c|c|c|c|c|c|c|c|c|}
\hline & & \multicolumn{2}{|c|}{$\begin{array}{l}\text { 3-month outcome (\%) } \\
(n=114)\end{array}$} & \multirow[b]{2}{*}{ OR } & \multirow[b]{2}{*}{$95 \% \mathrm{Cl}$} & \multicolumn{2}{|c|}{$\begin{array}{l}\text { 12-month outcome (\%) } \\
(\mathrm{n}=115)\end{array}$} & \multirow[b]{2}{*}{ OR } & \multirow[b]{2}{*}{$95 \% \mathrm{Cl}$} \\
\hline & & Favorable & Unfavorable & & & Favorable & Unfavorable & & \\
\hline \multirow{3}{*}{ Age } & $70-74$ years & $44,2 \%$ & $55,8 \%$ & 1,00 & \multirow{3}{*}{$\begin{array}{l}(0,52-2,96) \\
(0,42-2,80)\end{array}$} & $52,9 \%$ & $47,1 \%$ & 1,00 & \\
\hline & $75-79$ years & $38,9 \%$ & $61,1 \%$ & 1,25 & & $45,9 \%$ & $54,1 \%$ & 1,32 & $(0,57-3,09)$ \\
\hline & $>=80$ years & $42,3 \%$ & $57,7 \%$ & 1,08 & & $44,4 \%$ & $55,6 \%$ & 1,41 & $(0,55-3,59)$ \\
\hline \multirow{3}{*}{$\mathrm{CCl}^{\mathrm{a}}$} & 3 & $40,0 \%$ & $60,0 \%$ & 1,00 & \multirow{3}{*}{$\begin{array}{l}(0,36-2,01) \\
(0,35-2,47) \\
\end{array}$} & $53,7 \%$ & $46,3 \%$ & 1,00 & \\
\hline & 4 & $44,1 \%$ & $55,9 \%$ & 0,84 & & $44,4 \%$ & $55,6 \%$ & 1,45 & $(0,62-3,38)$ \\
\hline & 5 or more & $41,7 \%$ & $58,3 \%$ & 0,93 & & $44,0 \%$ & $56,0 \%$ & 1,48 & $(0,57-3,83)$ \\
\hline \multirow{2}{*}{ Sex } & Female & $45,2 \%$ & $54,8 \%$ & 1,00 & \multirow[b]{2}{*}{$(0,73-5,77)$} & $53,3 \%$ & $46,7 \%$ & 1,00 & \\
\hline & Male & $28,6 \%$ & $71,4 \%$ & 2,06 & & $30,4 \%$ & $69,6 \%$ & 2,60 & $(0,98-6,93)$ \\
\hline \multirow{3}{*}{$\begin{array}{l}\text { Antithrombotic } \\
\text { medication }\end{array}$} & None & $43,0 \%$ & $57,0 \%$ & 1,00 & \multirow{3}{*}{$\begin{array}{l}(0,46-3,29) \\
(0,32-3,18) \\
\end{array}$} & $53,2 \%$ & $46,8 \%$ & 1,00 & \\
\hline & Antiplatelet & $38,1 \%$ & $61,9 \%$ & 1,23 & & $33,3 \%$ & $66,7 \%$ & 2,27 & $(0,83-6,23)$ \\
\hline & Anticoagulant & $42,9 \%$ & $57,1 \%$ & 1,01 & & $46,7 \%$ & $53,3 \%$ & 1,30 & $(0,43-3,92)$ \\
\hline \multirow{2}{*}{ SAH grade ${ }^{a}$} & Good (WFNS I-III) & $59,7 \%$ & $40,3 \%$ & 1,00 & \multirow[b]{2}{*}{$(3,22-21,15)$} & $64,7 \%$ & $35,3 \%$ & 1,00 & \\
\hline & Poor (WFNS IV-V) & $15,2 \%$ & $84,8 \%$ & $8,25+$ & & $23,9 \%$ & $76,1 \%$ & $5,83+$ & $(2,52-13,52)$ \\
\hline \multirow{2}{*}{$\begin{array}{l}\text { Thick and diffuse } \\
\text { bleeding pattern* }\end{array}$} & No & $61,5 \%$ & $38,5 \%$ & 1,00 & \multirow[b]{2}{*}{$(1,12-6,78)$} & $70,4 \%$ & $29,6 \%$ & 1,00 & \\
\hline & Yes & $36,8 \%$ & $63,2 \%$ & $2,75^{+}$ & & $42,5 \%$ & $57,5 \%$ & $3,21+$ & $(1,27-8,13)$ \\
\hline \multirow{2}{*}{ Presence of IVH* } & No & $60,5 \%$ & $39,5 \%$ & 1,00 & \multirow[b]{2}{*}{$(1,37-6,88)$} & $71,1 \%$ & $28,9 \%$ & 1,00 & \\
\hline & Yes & $33,3 \%$ & $66,7 \%$ & $3,07+$ & & $38,2 \%$ & $61,8 \%$ & $3,98+$ & $(1,72-9,22)$ \\
\hline \multirow{2}{*}{ Presence of $\mathrm{ICH}^{*}$} & No & $50,7 \%$ & $49,3 \%$ & 1,00 & \multirow[b]{2}{*}{$(1,14-5,81)$} & $52,9 \%$ & $47,1 \%$ & 1,00 & \multirow[b]{2}{*}{$(0,69-3,15)$} \\
\hline & Yes & $28,6 \%$ & $71,4 \%$ & $2,57+$ & & $43,2 \%$ & $56,8 \%$ & 1,48 & \\
\hline \multirow{2}{*}{$\begin{array}{l}\text { Acute } \\
\text { hydrocephalus }\end{array}$} & No & $47,3 \%$ & $52,7 \%$ & 1,00 & \multirow[b]{2}{*}{$(0,71-3,18)$} & $52,7 \%$ & $47,3 \%$ & 1,00 & \multirow[b]{2}{*}{$(0,65-2,84)$} \\
\hline & Yes & $37,3 \%$ & $62,7 \%$ & 1,51 & & $45,0 \%$ & $55,0 \%$ & 1,36 & \\
\hline
\end{tabular}

* one missing value

$+p<0.05$

CCI: Charlson Comorbidity Index, ICH: intracerebral hemorrhage, IVH: intraventricular hemorrhage, WFNS: World Federation of Neurosurgical Societies grading scale 


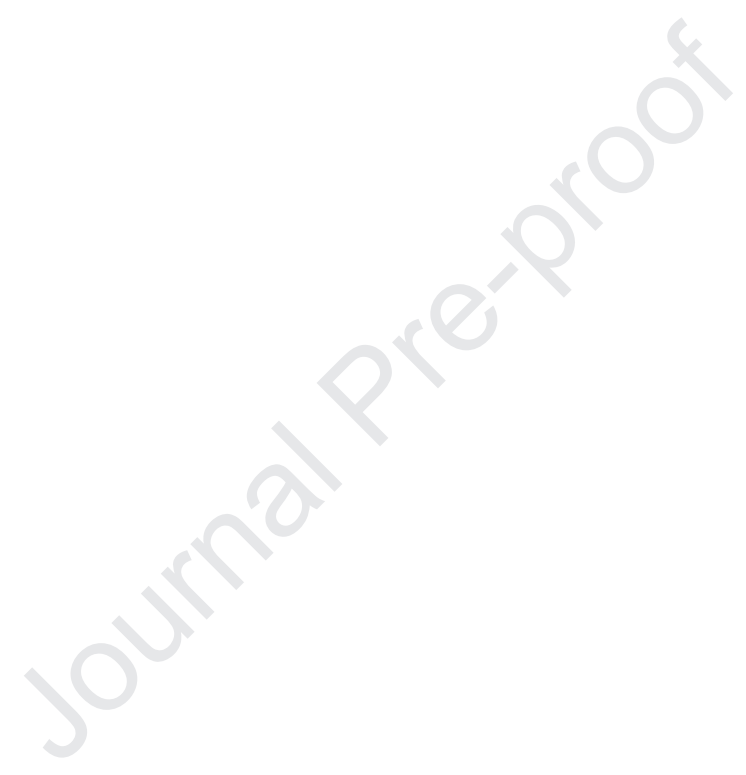




\section{Table 3}

Results of the multivariable regression analyses for outcomes at 3 and 12 months after aneurysmal subarachnoid hemorrhage, including age as a continuous variable, clinical grade, bleeding pattern, presence of intraventricular hemorrhage, presence of intracerebral hemorrhage and acute hydrocephalus. Odds ratios with $95 \%$ confidence intervals for unfavorable outcome are shown.

\begin{tabular}{|c|c|c|c|c|}
\hline & \multicolumn{2}{|c|}{$\begin{array}{l}\text { 3-month outcome } \\
(n=112)\end{array}$} & \multicolumn{2}{|c|}{$\begin{array}{l}\text { 12-month outcome } \\
(n=113)\end{array}$} \\
\hline & & $95 \% \mathrm{Cl}$ & & $95 \% \mathrm{Cl}$ \\
\hline Age & 1,03 & $(0,93-1,14)$ & 1,06 & $(0,96-1,16)$ \\
\hline WFNS IV-V vs I-III & $5,78^{*}$ & $(2,03-16,42)$ & $4,65^{*}$ & $(1,73-12,48)$ \\
\hline Thick and diffuse clot & 1,13 & $(0,37-3,42)$ & 1,51 & $(0,47-4,78)$ \\
\hline Presence of IVH & 2,05 & $(0,79-5,32)$ & $2,80^{*}$ & $(1,09-7,25)$ \\
\hline Presence of ICH & 2,04 & $(0,76-5,50)$ & 0,98 & $(0,37-2,57)$ \\
\hline Acute hydrocephalus & 1,09 & $(0,40-2,98)$ & 0,77 & $(0,29-2,05)$ \\
\hline
\end{tabular}

Cl: Confidence interval, CCl: Charlson Comorbidity Index, WFNS: World Federation of Neurosurgical Societies grading scale 
3 months $(n=114)$

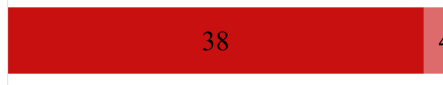

$0 \% \quad 10 \% \quad 20 \% \quad 30 \% \quad 40 \%$

$80 \%$

$90 \%$

$100 \%$

- Dead

Severe disability, living at home

$$
\text { - Vegetative state }
$$$$
\text { - Moderate disability }
$$

$\square$ Severe disability, living in an institute n Good recovery 


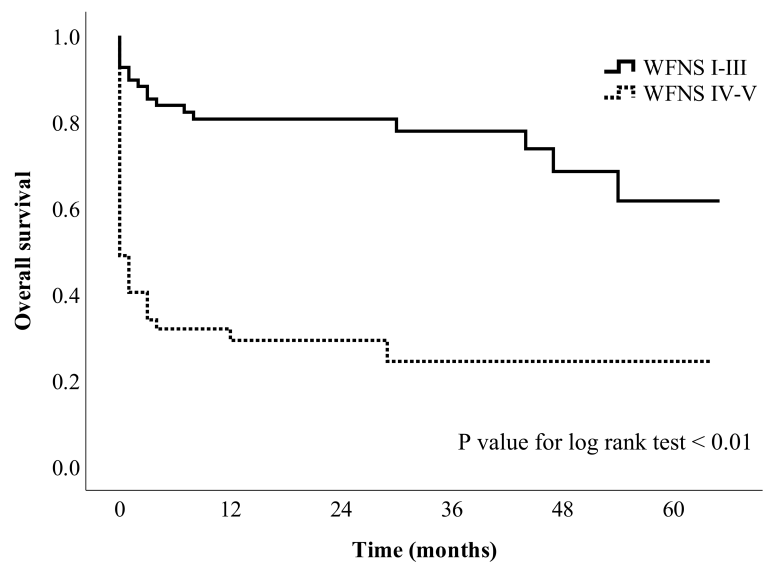




\section{Abbreviations list}

$\begin{array}{ll}\text { aSAH } & \text { Aneurysmal subarachnoud hemorrhage } \\ \text { CCI } & \text { Charlson Comorbidity Index } \\ \text { CI } & \text { Confidence interval } \\ \text { CT } & \text { Computed tomography } \\ \text { CTA } & \text { Computed tomography angiography } \\ \text { DNR } & \text { Do-not-resuscitate } \\ \text { EVD } & \text { External ventricular drain } \\ \text { GCS } & \text { Glasgow Coma Scale } \\ \text { GCS-m } & \text { Glasgow Coma Scale motor score } \\ \text { GOS } & \text { Glasgow Outcome Scale } \\ \text { IA } & \text { Intracranial aneurysm } \\ \text { ICD } & \text { International Statistical Classification of Diseases and Related Health } \\ \text { ICH } & \text { Problems } \\ \text { ICU } & \text { Intracerebral hemorrhage } \\ \text { IQR } & \text { Intensive care unit } \\ \text { IVH } & \text { Interquartile range } \\ \text { OR } & \text { Intraventricular hemorrhage } \\ \text { SD } & \text { Odds ratio } \\ \text { WFNS } & \text { Standard deviation }\end{array}$




\section{Declaration of interests}

$\bigotimes$ The authors declare that they have no known competing financial interests or personal relationships that could have appeared to influence the work reported in this paper.

$\square$ The authors declare the following financial interests/personal relationships which may be considered as potential competing interests: 